\title{
Integrating storm surge modeling with traffic data analysis to evaluate the effectiveness of hurricane evacuation
}

\author{
Wenrui HUANG ${ }^{\mathrm{a}}$, Kai YIN ${ }^{\mathrm{b}, \mathrm{a}^{*}}$, Mahyar GHORBANZADEH ${ }^{\mathrm{a}}$, Eren OZGUVEN ${ }^{\mathrm{a}}$, Sudong XU $\mathbf{O}^{\mathrm{b}}$, Linoj VIJAYAN \\ ${ }^{a}$ Department of Civil and Environmental Engineering, Florida A\&M University-Florida State University College of Engineering, \\ Tallahassee, FL 32310, USA \\ ${ }^{b}$ Department of Port, Waterway and Coastal Engineering, School of Transportation, Southeast University, Nanjing 211189, \\ China \\ *Corresponding author.E-mail: kaiyin@seu.edu.cn
}

C The Author(s) 2021. This article is published with open access at link.springer.com and journal.hep.com.cn

\begin{abstract}
An integrated storm surge modeling and traffic analysis were conducted in this study to assess the effectiveness of hurricane evacuations through a case study of Hurricane Irma. The Category 5 hurricane in 2017 caused a record evacuation with an estimated 6.8 million people relocating statewide in Florida. The Advanced Circulation (ADCIRC) model was applied to simulate storm tides during the hurricane event. Model validations indicated that simulated pressures, winds, and storm surge compared well with observations. Model simulated storm tides and winds were used to estimate the area affected by Hurricane Irma. Results showed that the storm surge and strong wind mainly affected coastal counties in south-west Florida. Only moderate storm tides (maximum about $2.5 \mathrm{~m}$ ) and maximum wind speed about $115 \mathrm{mph}$ were shown in both model simulations and Federal Emergency Management Agency (FEMA) post-hurricane assessment near the area of hurricane landfall. Storm surges did not rise to the 100-year flood elevation level. The maximum wind was much below the design wind speed of 150-170 mph (Category 5) as defined in Florida Building Code (FBC) for south Florida coastal areas. Compared with the total population of about 2.25 million in the six coastal counties affected by storm surge and Category 1-3 wind, the statewide evacuation of approximately 6.8 million people was found to be an over-evacuation due mainly to the uncertainty of hurricane path, which shifted from south-east to south-west Florida. The uncertainty of hurricane tracks made it difficult to predict the appropriate storm surge inundation zone for evacuation. Traffic data were used to analyze the evacuation traffic patterns. In south-east Florida, evacuation traffic started 4 days before the hurricane's arrival. However, the hurricane path shifted and eventually landed in south-west Florida, which caused a high level of evacuation traffic in south-west Florida. Over-evacuation caused Evacuation Traffic Index (ETI) to increase to $200 \%$ above normal conditions in some sections of highways, which reduced the effectiveness of evacuation. Results from this study show that evacuation efficiency can be improved in the future by more accurate hurricane forecasting, better public awareness of real-time storm surge and wind as well as integrated storm surge and evacuation modeling for quick response to the uncertainty of hurricane forecasting.
\end{abstract}

KEYWORDS storm surge modeling, traffic, evacuation, Hurricane Irma

\section{Introduction}

Storm surge is one of the major hazards affecting hurricane evacuation planning and operations in United States. When a hurricane approaches the coast,

Article history: Received Oct 25, 2020; Accepted Jul 4, 2021 emergency management agencies and residents rely on the forecasting information relating to hurricane tracks and storm surge for preparedness and evacuation planning. Traditionally, storm surge and evacuation planning are two different research areas, with the literature mainly focusing on an individual area such as evacuation traffic only [1,2] or storm surge only [3-14]. 
Literature on integrating storm surge study with traffic analysis for hurricane evacuation assessments and planning is scarce. Based on a case study of Hurricane Irma in 2017 landed in Florida, this paper presents an integrated study of storm surge modeling with evacuation traffic data analysis to enhance the understanding of how storm surge predictions affect evacuation traffic to support hurricane preparedness and responses.

Numerical models have often been used in predicting storm surges to support coastal hazard mitigation and evacuations. $\mathrm{Xu}$ et al. [5] conducted hydrodynamic modeling in Colombo, Sri Lanka. Ullman et al. [6] integrated the advanced circulation (ADCIRC) model and a hydrological model to investigate the combined effects of storm surge and rainfall runoff on coastal flooding. Wang et al. [7] studied Hurricane Michael's impacts on morphological and sedimentological features along the north-west Florida coast. Shen et al. [8] modeled Typhoon-induced storm surge and waves in the Yangtze River Estuary. Ding et al. [9] coupled a fully-integrated process model and a parametric cyclonic wind model to investigate storm surge and wave. Wang and Yang [10] investigated the nonlinear effects of sea-level rise on storm surge. Xiao et al. [11] studied the extent of saltwater intrusion into the surficial aquifer affected by storm surge in coastal east-central Florida. Pan and Liu [12] applied a storm surge model to study the effect of human projects on storm surge in the Yangtze Estuary. Sun et al. [13] studied a risk analysis of seawall overtopping by storm surge during a typhoon. Li et al. [14] conducted a numerical study of combined wave overtopping and storm surge overflow of HPTRM strengthened levee.

Hurricane evacuations [1,2] are often based on the forecasting of coastal hazard areas to be affected by storm surges and wind. If storm surge and wind are overestimated because of the uncertainty of hurricane forecasting, too many people may have to be evacuated, which may cause traffic congestion and the widespread gasoline shortage. Massive evacuation during Hurricane Irma is a very good case study for analysis of evacuation traffic. Hurricane Irma, the first Category 5 hurricane in the 2017 Atlantic hurricane season, was one of the strongest and most catastrophic hurricanes recorded in the Atlantic basin $[15,16]$. Owing to its strong winds, heavy rains, and high surf across the Caribbean Islands and the south-eastern United States Irma caused 44 direct deaths in these areas, including 7 direct deaths in the United States [16]; most causalities were in the Caribbean Islands, however, where Irma's winds were the strongest. It was estimated that this hurricane caused costs of approximately 50.0 billion USD in wind and water damage in the United States [17], making Irma the fifthcostliest hurricane to affect the United States. Hurricane Irma originated from a tropical wave in the west coast of Africa on August 27, 2017 [16]. It then became a tropical depression and further developed into a tropical storm in the region of western of Cabo Verde Islands on August 30. Once Irma entered the Florida Straits, it turned northward and intensified to Category 4 strength and then made landfall near Cudjoe Key on September 10, with a minimum central pressure of $931 \mathrm{mb}$. After moving away from the Florida Keys, Irma weakened to a Category 3 hurricane. As a Category 3 hurricane, it made its final landfall near Marco Island (Fig. 1), Florida later on September 10, with a minimum central pressure of $936 \mathrm{mb}$. Owing to the influence of land, Irma weakened quickly and became a Category 2 hurricane on 00:00 UTC

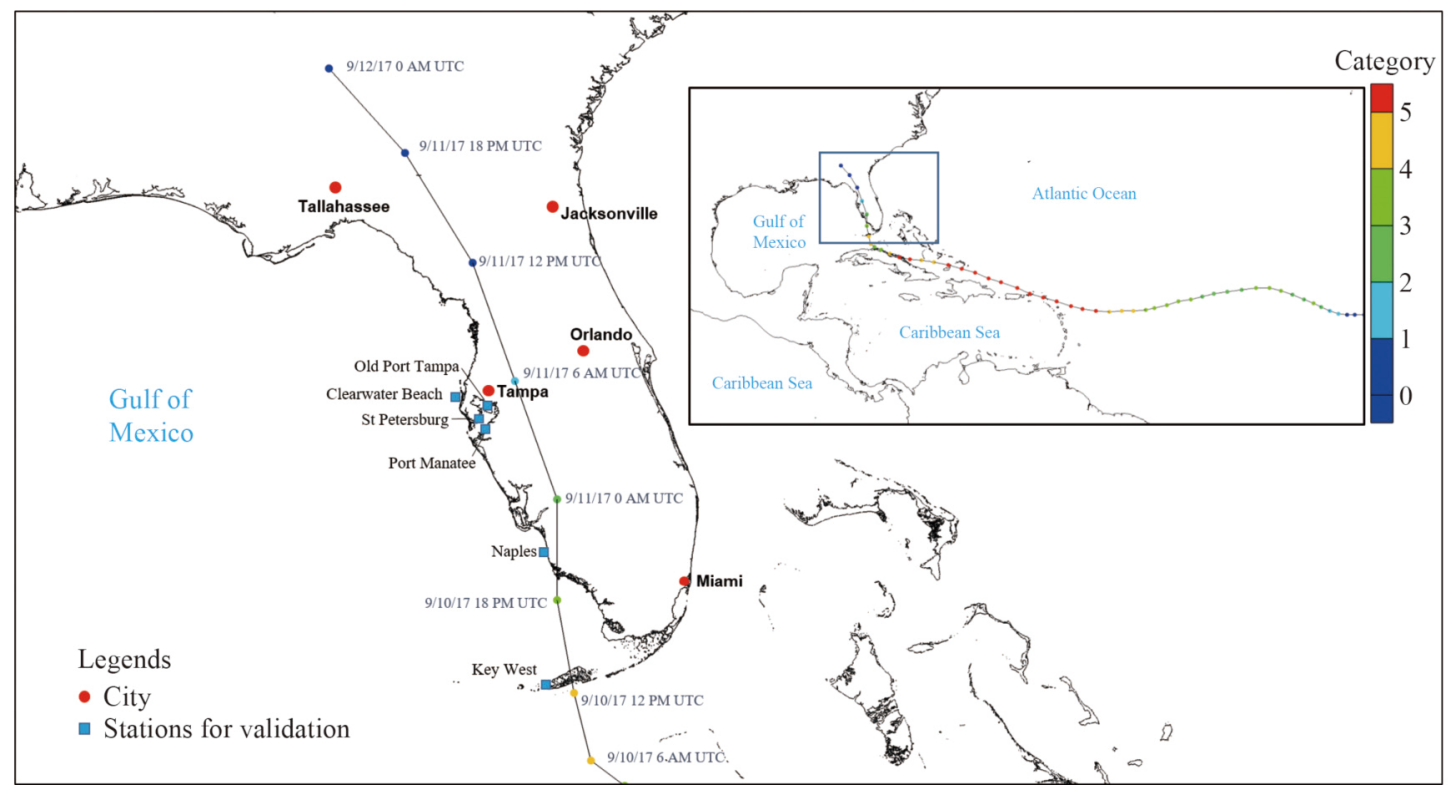

Fig. 1 Study area and the track of Hurricane Irma in September, 2017. 
September 11. A few hours later, it further weakened to be a Category 1 hurricane. While moving northward over Florida, it became a tropical storm by 12:00 UTC September 11, 2017. Around the time when Irma made its final landfall near Marco Island, a spotter in Marco Island reported a maximum gust of 112 knots, and a 123-knot wind gust was reported in Naples pier. In the MiamiDade and Broward County metro area, almost all of the inland observations reported sustained winds just below hurricane force. A Key West, FL, station recorded wind speed of $32.2 \mathrm{~m} / \mathrm{s}$, which was the highest wind speed recorded at National Oceanic and Atmospheric Administration (NOAA) water level stations along the eastern Gulf of Mexico and the south-east United States during Hurricane Irma. Meanwhile, the peak water level at seven stations along the south-east United States exceeded their respective historical maximum water level values. The station at the I-295 Bridge, FL, recorded a peak water level of $1.603 \mathrm{~m}$ above mean higher high water (MHHW) [18].

Analysis of traffic data during Hurricane Irma evacuation will benefit hurricane hazard preparedness and responses in the future. Because of the high density of population near the coast, potential storm surge and winds are the major factors for residents to consider in making their decisions for evacuation. Valuable real-time traffic data during Hurricane Irma were collected by the Florida Department of Transportation (FDOT) telemetered traffic monitoring sites (TTMS) at 63 locations [19]. A week before Hurricane Irma struck the Florida coast, the Florida Governor declared a state of emergency, based on potential storm surge area of the forecast hurricane track. With both the Atlantic and Gulf coasts of the state threatened, record evacuations ensued with an estimated 6.8 million people relocating statewide [19]. A mandatory evacuation order was issued for all Monroe County - though roughly $25 \%$ of residents did not evacuate-and portions of 23 other counties. The large-scale evacuation strained roadways, with gridlock and traffic congestions reported by FDOT [19] along Interstates Highway 95 and 75, and Florida's Turnpike (Fig. 2). To relieve the traffic congestions, FDOT opened the highway shoulder for evacuation traffic (Fig. 2). A total of 191764 people sought refuge in public shelters. All major airports saw disruption of services, resulting in the cancellation of 9000 flights. However, the uncertainty of hurricane tracks causes difficulties in evacuation traffic. Three days before the hurricane landfall, it was forecast to move (as shown later in Fig. 13) along the Florida east coast, which caused a high level of evacuation traffic in the east coast. Some residents in south Florida drove from east coast to the west coast. However, Hurricane Irma finally made landfall in the west coast (Fig. 1).

In this study, storm surge modeling and traffic analysis

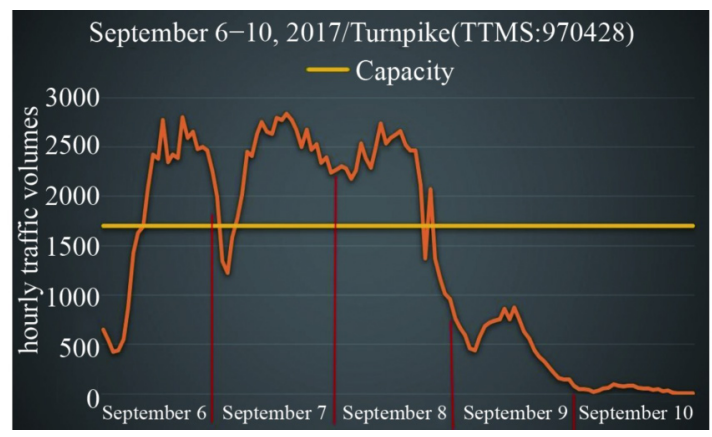

Fig. 2 Hurricane Irma evacuation traffic showing traffic congestions in Florida Turnpike in 2007 evacuation.

is conducted to evaluate the effectiveness of Hurricane Irma evacuation. Storm surge and wind are used to identify hazard-affected counties, which can be used to estimate the number of evacuees. Whether the evacuation was reasonable or an overreaction can be evaluated by comparing the number of people living in areas ultimately affected by the storm surge and wind to the 6.8 million people evacuated during Hurricane Irma. Uncertainty of hurricane forecasting is a challenging issue for emergency evacuation. Large amount of statewide traffic data are used to investigate the evacuation traffic patterns and traffic congestions in response to the shift of the hurricane track in forecasts. Deficiencies in evacuation planning and operation during Hurricane Irma are analyzed. Results from this study will be helpful for emergency management agencies and coastal residents in providing improved understanding of the storm surge dynamics for better preparedness against hurricanes in the future.

\section{Numerical modeling methodology for storm surge and tides}

\subsection{Numerical model}

To simulate storm surge on the Florida coast induced by Hurricane Irma, the ADCIRC model, developed by Luettich et al. [20], was employed. This model has been widely applied to storm surge modeling around the world [4-6,16-18,20]. It can be applied to simulate water levels and currents through solving the depth-integrated continuity equation and two-dimensional depth integrated momentum equations. These equations are solved by finite element method in space and finite difference method in time. The basic governing continuity (Eq. (1)) and momentum (Eqs. (2) and (3)) of the model are expressed in Cartesian coordinates:

$$
\frac{\partial \zeta}{\partial t}+\frac{\partial U H}{\partial x}+\frac{\partial V H}{\partial y}=0
$$




$$
\begin{aligned}
& \frac{\partial U}{\partial t}+U \frac{\partial U}{\partial x}+V \frac{\partial U}{\partial y}-f V= \\
& -\frac{\partial}{\partial x}\left[\frac{p_{\mathrm{s}}}{\rho_{0}}+g(\zeta-\alpha \eta)\right]+\frac{1}{H} M_{X}+\frac{\tau_{\mathrm{S} X}}{\rho_{0} H}-\tau_{*} U \\
& \frac{\partial V}{\partial t}+U \frac{\partial V}{\partial x}+V \frac{\partial V}{\partial y}+f U= \\
& \quad-\frac{\partial}{\partial y}\left[\frac{p_{\mathrm{s}}}{\rho_{0}}+g(\zeta-\alpha \eta)\right]+\frac{1}{H} M_{Y}+\frac{\tau_{\mathrm{S} Y}}{\rho_{0} H}-\tau_{*} V
\end{aligned}
$$

where $t$ is the time; $x, y$ are the horizontal coordinates, aligned in the east and north directions respectively; $\zeta$ is the free surface elevation; $U$ is the depth-averaged horizontal velocity in $x$ direction; $V$ is the depth-averaged horizontal velocity in $y$ direction; $H$ is the total water column depth, $h+\zeta ; h$ is the bathymetric depth; $f=2 \Omega \sin \phi$ is the Coriolis parameter; $\Omega$ is the angular speed of the earth; $\phi$ is the degrees latitude; $p_{\mathrm{s}}$ is the atmospheric pressure at the free surface; $g$ is the acceleration due to gravity; $\eta$ is the Newtonian equilibrium tide potential; $a$ is the earth elasticity factor; $\rho_{0}$ is the reference density of water; $\tau_{\mathrm{S} X}$ is the applied free surface stress in $x$ direction; $\tau_{\mathrm{S} Y}$ is the applied free surface stress in $y$ direction; $\tau_{*}=C_{\mathrm{f}} \sqrt{U^{2}+V^{2}} / H$ is the bottom stress; $C_{\mathrm{f}}$ is the bottom friction coefficient; $M_{X}=E_{\mathrm{h} 2}\left[\partial^{2} U H / \partial x^{2}+\partial^{2} U H / \partial y^{2}\right]$ is the depth-integrated momentum dispersion in $x$ direction; $M_{Y}=E_{\mathrm{h} 2}\left[\partial^{2} V H /\right.$ $\left.\partial x^{2}+\partial^{2} V H / \partial y^{2}\right]$ is the depth-integrated momentum dispersion in $y$ direction; $E_{\mathrm{h} 2}$ is the horizontal eddy viscosity. Through using highly flexible, unstructured grids, ADCIRC can precisely fit irregular coastline and islands, and conveniently adopt high grid resolution in the study area while low grid resolution in others. ADCIRC has shown good success in modeling tides, storm surge and wind driven circulation in many geographical regions including the Gulf of Mexico.

ADCIRC simulations require wind and pressure as meteorological forcing and empirical formula using observed parameters of the hurricane at each time steps were used to model storm surge. Specifically, a temporally and spatially varying wind field was calculated based on the Holland pressure (Eq. (4)), and the gradient balance wind velocity (Eq. (5)).

$$
\begin{gathered}
P(r)=P_{0}+\left(P_{\infty}-P_{0}\right) \exp \left[-\left(\frac{R_{\max }}{r}\right)^{B}\right] \\
V_{\mathrm{G}}(r)=-\frac{f r}{2} \\
+\left\{\left(\frac{f r}{2}\right)^{2}+\frac{\left(P_{\infty}-P_{0}\right) B}{\rho}\left(\frac{R_{\max }}{r}\right)^{B} \exp \left[-\left(\frac{R_{\max }}{r}\right)^{B}\right]\right\}^{1 / 2},
\end{gathered}
$$

where $P(r)$ is the pressure at a radial distance $r$ from typhoon center; $P_{\infty}$ is the ambient or environmental pressure $(1013 \mathrm{mb}) ; P_{0}$ is the typhoon central pressure; $r$ is the distance from calculating point to typhoon center; $R_{\max }$ is the radius of maximum winds; $B$ is Holland's pressure profile parameter; $V_{\mathrm{G}}(r)$ is the gradient balance wind velocity; $\rho$ is the density of air and $f$ is the Coriolis parameter. $R_{\max }$ and $B$ were determined by observations of wind and pressures.

\subsection{Model setup}

To simulate the generation and propagation of storm surge during Irma, this study utilized a model domain that was large enough to cover Irma's 5-d movement track before it made landfall in the Florida Keys. The computational domain covers the entire Gulf of Mexico and Caribbean Sea as well as part of the North-western Atlantic Ocean. An unstructured triangular mesh system, which fits well to irregular coastline and islands (Fig. 3(a)), was used for the computation domain. It consists of 87313 nodes and 169624 triangular elements with a varying resolution ranging from $25 \mathrm{~km}$ on the edges of the model in Atlantic Ocean to less than $1 \mathrm{~km}$ near the coast of Florida. The spherical coordinate system is adopted for this model mesh. The bathymetry at each node (Fig. 3(b)) was calculated based on General Bathymetric Chart of the Oceans (available at the website of GEBCO); calculated bathymetry within the model domain ranges from approximately $8400 \mathrm{~m}$ in the deep ocean to less than $1 \mathrm{~m}$ in the coastal area. The model was forced by tide constituents and $10 \mathrm{~m}$ height wind field. Only one open-ocean tidally forced boundary was set up

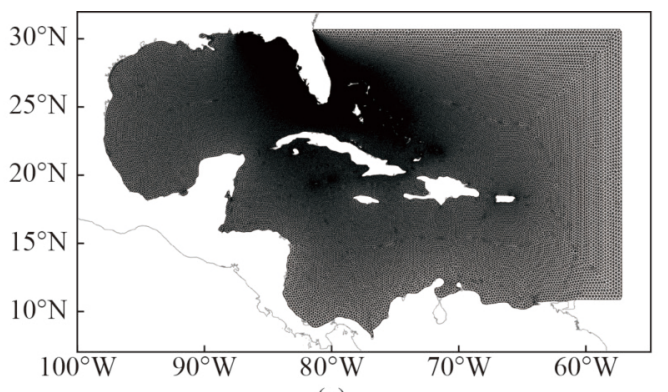

(a)

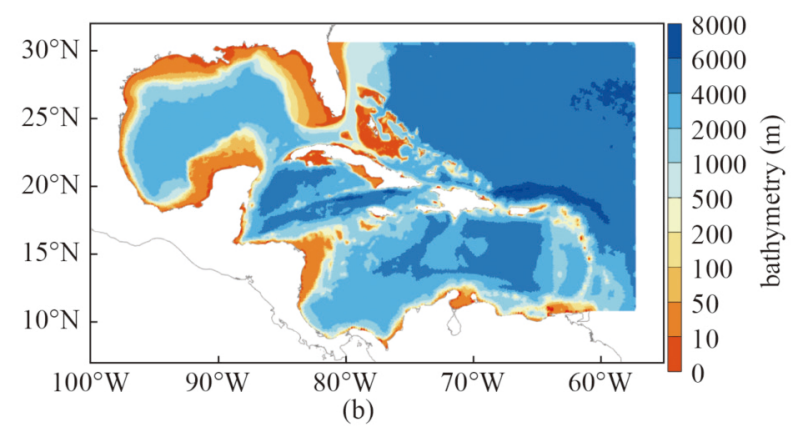

Fig. 3 (a) Computational model mesh; (b) bathymetry (m). 
for the two-dimensional ADCIRC model. At the open boundary, the principal tidal constituents obtained from Le-provost data set were enforced. Simulation time step was set as $1 \mathrm{~s}$. Bottom friction for hydrodynamic modeling was parameterized using the spatially varying Manning coefficients, which was ranging from 0.016 to 0.035 in accordance with the varying bathymetry of model domain.

\section{Model validation and time series analysis}

Time series of observations of atmospheric pressure, wind speeds, and storm tides at several NOAA stations were used to validate model simulations. In addition, the time series of both observations and model simulations were used to analyze the dynamic responses of air pressure, wind speeds, and storm tides in responses to the hurricane. Simulation of Hurricane Irma storm surge began on September 6, 2017 (0000 UTC) following a ramp-up period of $2 \mathrm{~d}$. It ended at 23:00 UTC on September 11, 2017, which coincided, with the last available Tropical Cyclone Best Track data. Observed data sets were obtained from NOAA's Center for Operational Oceanographic Products and Services (COOPS).

Accurate calculation of atmosphere pressure and wind speed is essential in storm surge modeling. In this study, atmosphere pressure and wind speed were calculated by applying the Holland pressure (Eq. (3)) and the gradient balance wind velocity (Eq. (4)). Comparisons of the modeled and observed pressure as well as wind speeds during Irma at Key West, Naples, Old Port Tampa and Clearwater Beach stations are presented in Figs. 4 and 5. Wind speed substantially increased when the hurricane center made landfall near Naples. The wind speeds inside the typhoon core were substantially lower than those outside the typhoon core. Minimum pressure and maximum wind speed were all observed on September 10. Observed mean minimum pressure at these four stations was about $961.65 \mathrm{mb}$, while the simulated mean value was $961.38 \mathrm{mb}$. Comparisons suggest that there is no significant difference between the modeled and measured values of pressure and wind speeds. Averaged correlation coefficient and root-mean-square error of the simulated pressure from the measured are 0.98 and 3.19 $\mathrm{mb}$, respectively at these five stations. These two statistical indicators for wind speed are calculated to be 0.91 and $3.12 \mathrm{~m} / \mathrm{s}$. Therefore, the generated pressure and wind field can be used as forcing factors in the storm surge model. Time series of pressure and wind speed also show that, after Hurricane Irma made landfall near Marco Island and Naples, pressure gradually increased and wind speed decreased due to the effects of land and dryer air as the hurricane moved north through stations of Naples,

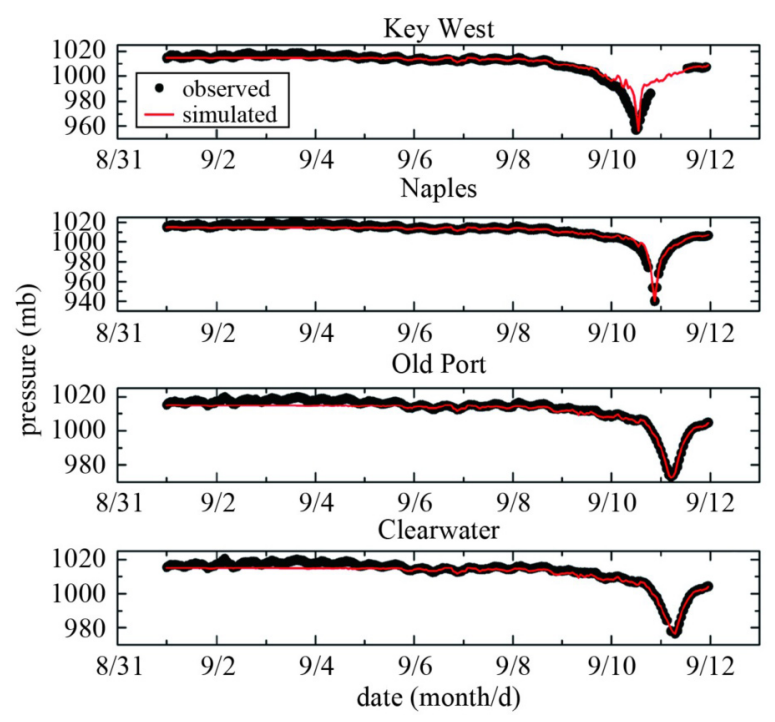

Fig. 4 Time series of model computed and observed pressure at NOAA coastal stations.
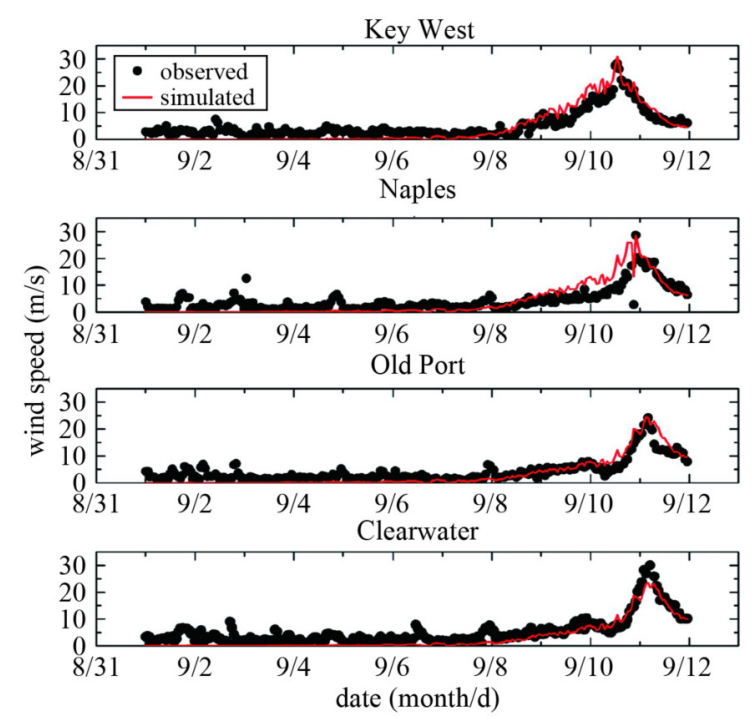

Fig. 5 Time series of model computed and observed wind speed at NOAA coastal stations.

\section{Old Port, and Clear Water (near Tampa).}

The modeled sea levels were compared to recorded data set at four NOAA coastal stations as shown in Fig. 6. Sea levels are referenced to mean sea level. The agreement between the modeled and observed sea levels is quite reasonable at each station with correlation coefficients of 0.86 or higher. Time series of modeled and observed sea levels indicate that the modeled storm surge and tides with respect to the peak value, peak time and trend all match well with the general trend of the observed data. Besides, obvious negative storm surge can be seen in these figures. During September 10, when this area was severely affected by Hurricane Irma, abnormally low sea levels occurred at these stations, such as $-1.45 \mathrm{~m}$ at St 

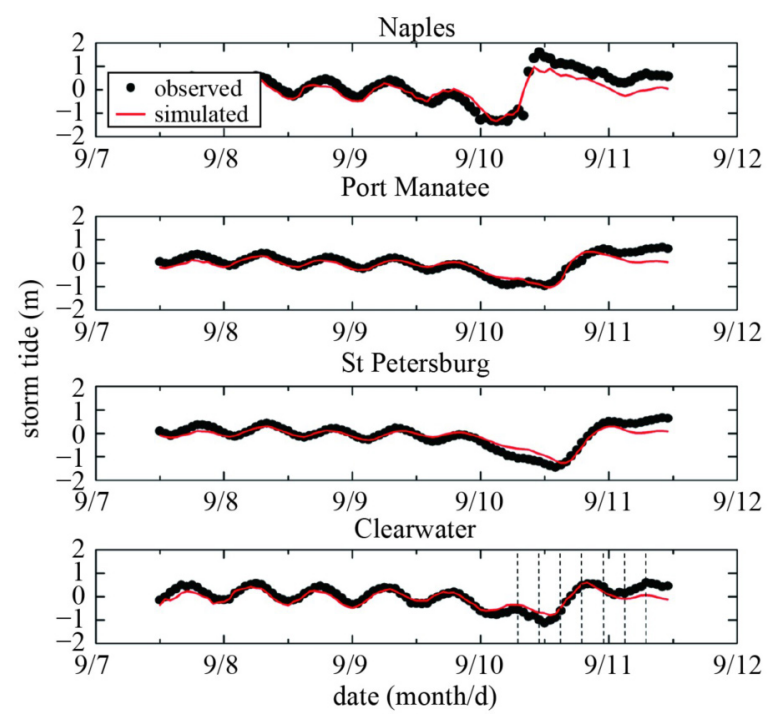

Fig. 6 Time series of model computed (line) and observed (dot) water levels caused by storm surge and tides at NOAA coastal stations.

Petersburg station. The above validations confirmed the capacity of the model to simulate storm surge in Florida's south-western coastal region. Hence, the model was applied to investigate estuarine response to Hurricane Irma. Summary of statistics of the model performance is given in Table 1 for atmosphere and wind speed, and Table 2 for storm tides.

\section{Model simulations of wind fields and storm tides}

Storm tide is the water level rise during a storm due to the combination of storm surge and the astronomical tide.

Table 1 Statistics (RMSE) of comparison between observed and simulated values of atmospheric pressure and wind speed

\begin{tabular}{lcc}
\hline stations & atmosphere pressure $(\mathrm{mb})$ & wind speed $(\mathrm{m} / \mathrm{s})$ \\
\hline Key West & 3.99 & 2.81 \\
Naples & 2.29 & 3.30 \\
Old Port Tampa & 2.03 & 2.48 \\
Clearwater Beach & 2.09 & 2.76 \\
\hline
\end{tabular}

Note: $R M S E=$ root mean square error.

Table 2 Statistics (RMSE) of comparison between observed and simulated values of storm tides

\begin{tabular}{lc}
\hline stations & storm tides $(\mathrm{m})$ \\
\hline Naples & 0.35 \\
Port Manatee & 0.21 \\
St Petersburg & 0.23 \\
Clearwater & 0.22 \\
\hline
\end{tabular}

Storm surge is affected by hurricane wind and pressure and by coastal topography and bathymetry. Having satisfactorily validated the storm surge model by comparing model simulations with observations as shown in Figs. 4-6, snapshots of model simulations of wind fields and water levels at different times are presented in Figs. 7-12 to demonstrate the dynamics of storm tides affected by the hurricane. The Florida Keys is a coral cay archipelago located off the southern coast of Florida, forming the southernmost portion of the continental United States, and acting like a long breakwater or barrier to protect the south-west Florida coast. The snapshots of storm surge distributions can be used to investigate how the Florida Keys may reduce the storm surge impacts on Florida coast. Tidal phases at each snapshot are shown in Fig. 6 of the time series of storm tides.

At 07:00 UTC, September 10, the hurricane eye was located south of the Florida Keys with winds between 20 and $30 \mathrm{~m} / \mathrm{s}$ (Fig. 7). Because the hurricane eye was still away from the coast, storm surge was not observed yet. However, the effect of Florida Keys on water levels can be viewed by the negative elevations north of the Florida Keys, because the Florida Keys acted as a barrier to block the water movement from the south to the north. As shown in Fig. 7(b), the water elevation in the corner area between Florida Keys and the Florida coast was about $0.5-1 \mathrm{~m}$ lower than other areas.

At 11:00 UTC, September 10, the hurricane center moved to Key West (Fig. 8). Wind speed was about $25-30 \mathrm{~m} / \mathrm{s}$ in Key West area, about $15-25 \mathrm{~m} / \mathrm{s}$ in Miami and Fort Myers areas, and about $10-15 \mathrm{~m} / \mathrm{s}$ in Tampa area. Because of the effects of low tide, water levels were generally lower than those at 7:00 am UTC in the region. A storm surge cone was shown near Key West, with the elevation about $1 \mathrm{~m}$ higher than the nearby waters. Due to the barrier effects of the Florida Keys that reduced the flows from the south to the north, water surface elevations north of the Florida Keys were generally lower than that in the south of the Florida Keys, with a maximum difference of about $1 \mathrm{~m}$. This shows that the Florida Keys acts as a barrier that effectively reduces storm surge elevation in the south-west Florida coast.

At 15:00 UTC, September 10, the hurricane center moved to the north of Key West, getting closer to the south-west Florida coast (Fig. 9). Wind speed was about $25-30 \mathrm{~m} / \mathrm{s}$ in Key West, about $20-25 \mathrm{~m} / \mathrm{s}$ in the Miami and Fort Myers areas, and about 10-15 in Tampa area. Because of the counter clockwise movement of hurricane wind, water levels increased to about $0.5-1 \mathrm{~m}$ on the eastern coast of Florida and to the south of Florida Keys. However, in the coastal waters of west Florida and north Florida Keys, water was driven away from the coast and Florida Keys. As a result, water surface elevations were lower than those in the east coast of Florida. For the areas between Florida Keys and south-west Florida coast, water 

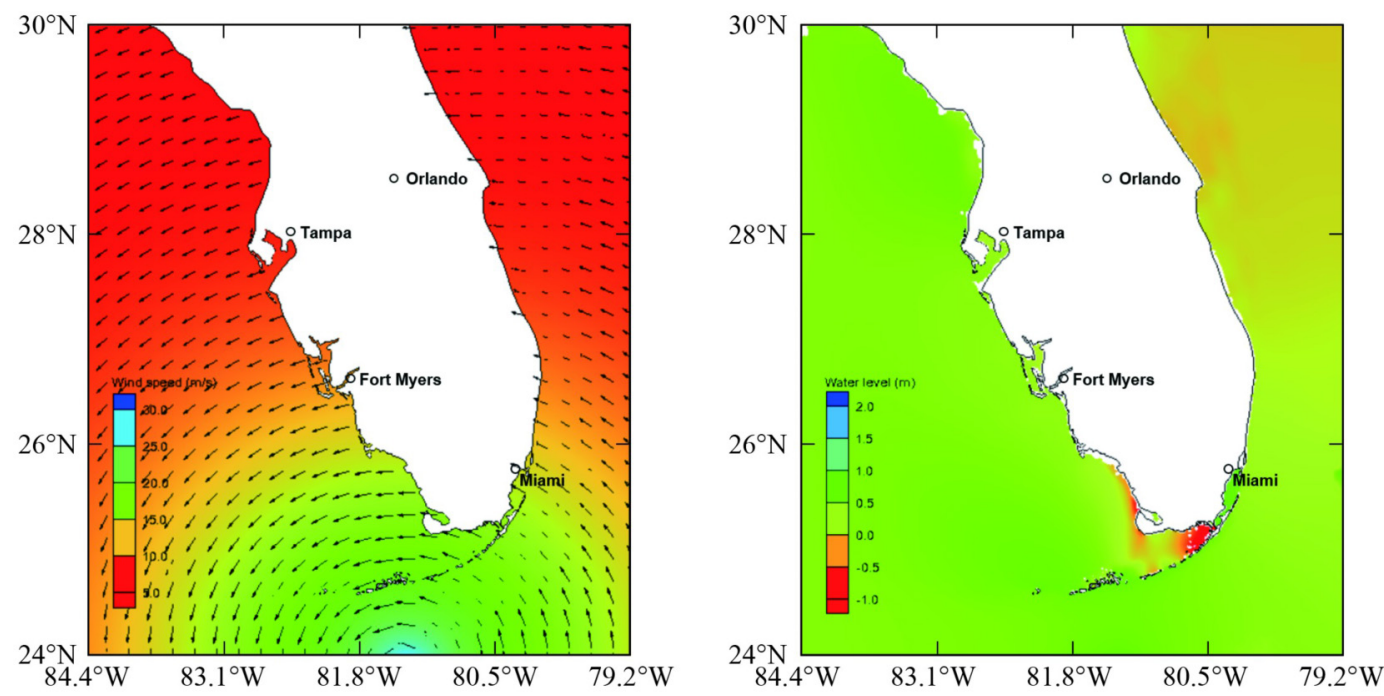

Fig. 7 Wind field and water levels at 07:00 UTC, September 10, 2017.
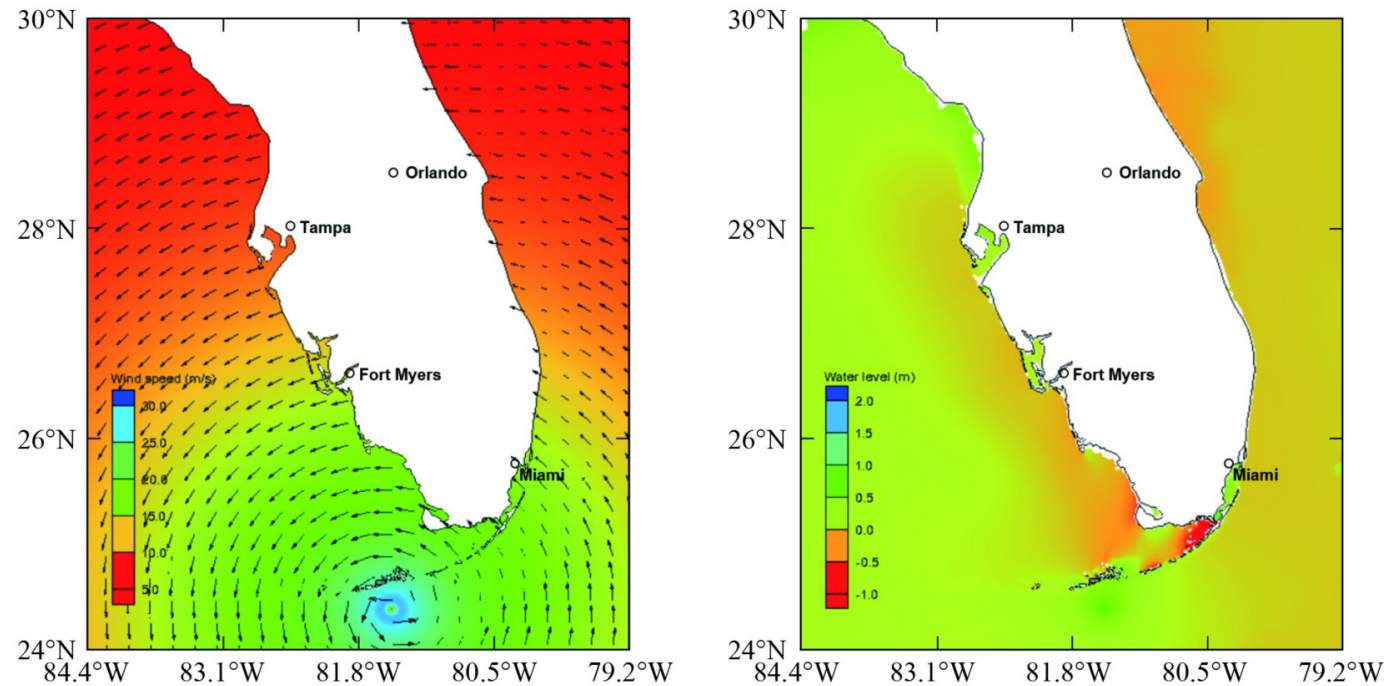

Fig. 8 Wind field and water levels at 11:00 UTC, September 10, 2017.
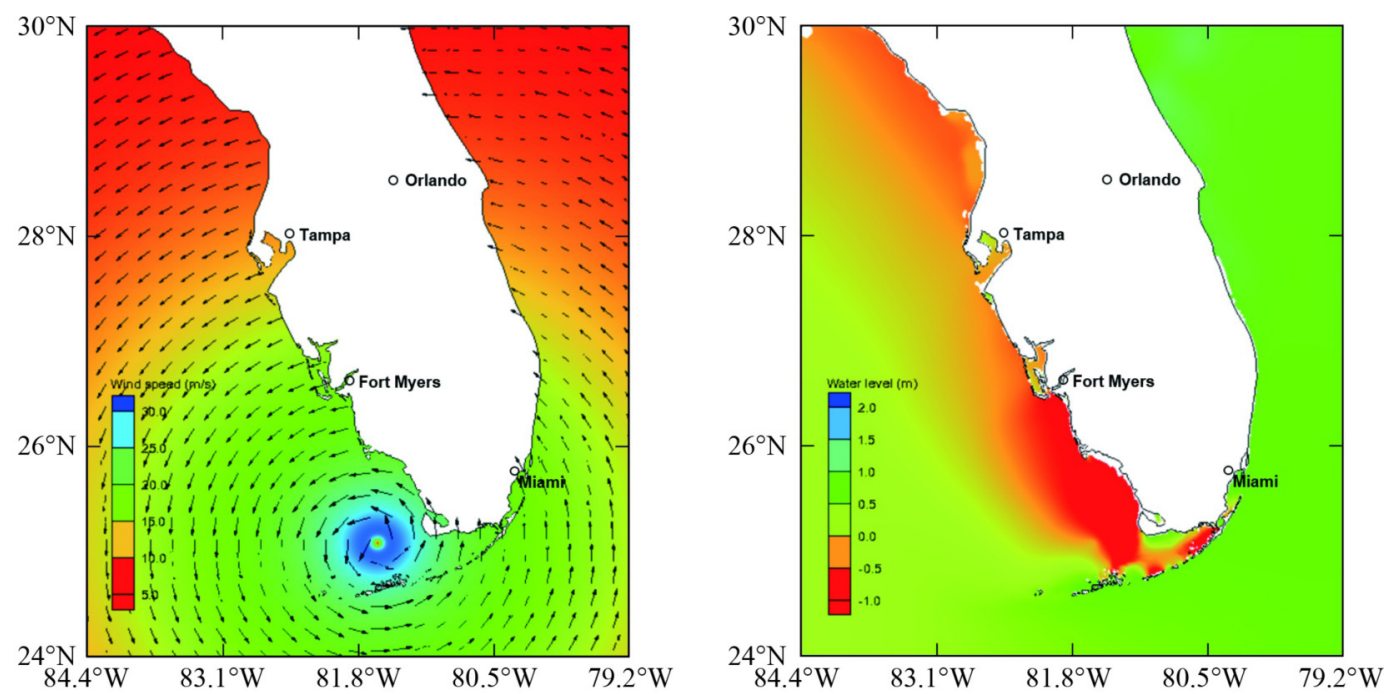

Fig. 9 Wind field and water levels at15:00 UTC, September 10, 2017. 

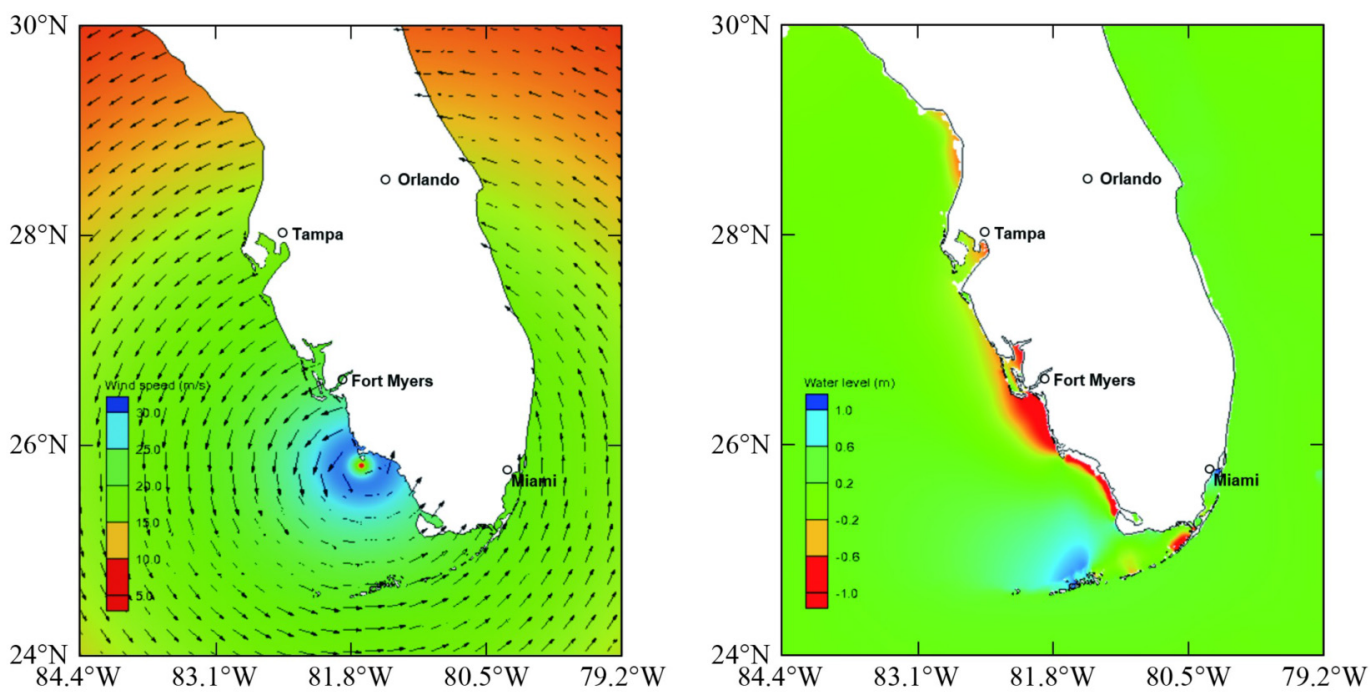

Fig. 10 Wind field and water levels at 19:00 UTC, September 10, 2017.
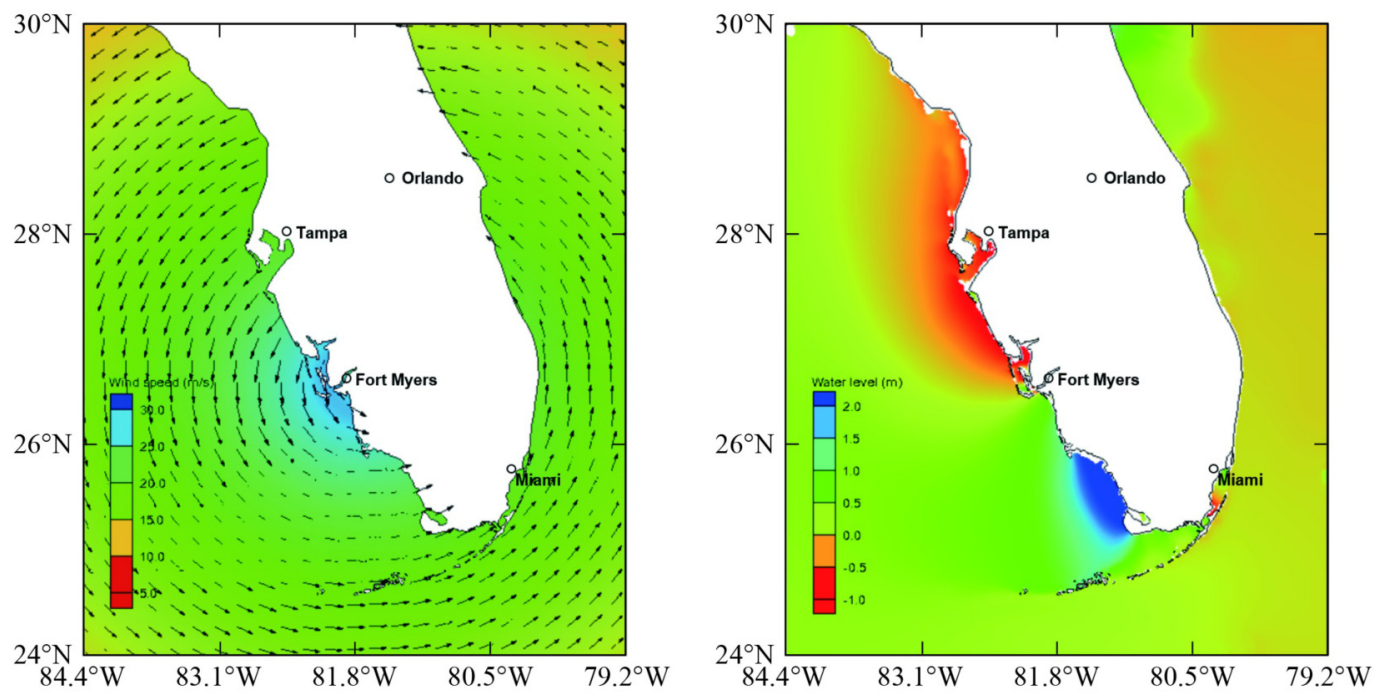

Fig. 11 Wind field and water levels at 23:00 UTC, September 10, 2017.
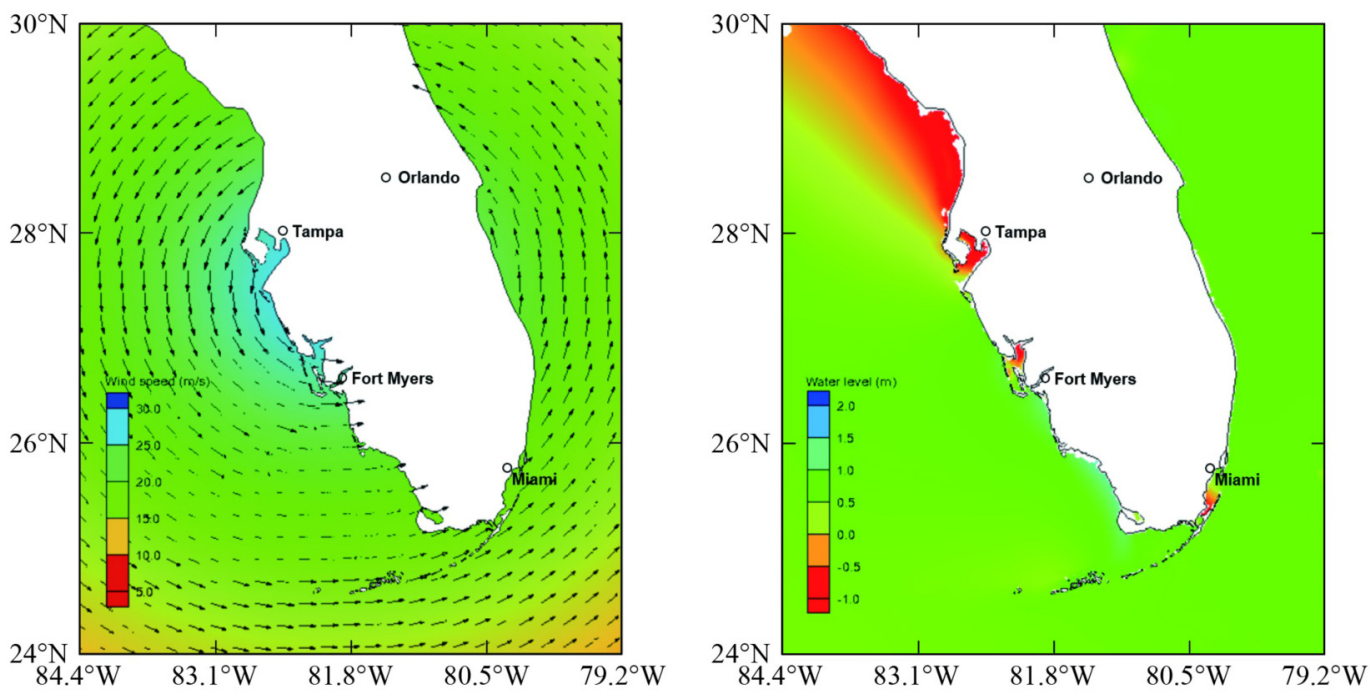

Fig. 12 Wind field and water levels, 03:00 UTC, September 11, 2017. 
surface elevation was about -0.5 to $-1 \mathrm{~m}$, about $1-2 \mathrm{~m}$ lower than those in Miami area, showing the negative storm surge. In Tampa Bay area, the water level was about 0 to $-0.5 \mathrm{~m}$.

At 19:00 UTC, September 10, the hurricane center made landfall near Marco Island in the south-west Florida, south of Fort Myers (Fig. 10). The wind speed was about 25-30 m/s near Fort Myers, about 15-25 m/s in Miami and Tampa areas. Because of the counter clockwise rotation of hurricane winds, wind directions were away from the coast in the north of the hurricane center, and toward the coast in locations south of the hurricane center. Therefore, water levels in the south of the hurricane center near Key West increased to about $1 \mathrm{~m}$, while water levels near Fort Myers decreased to $-1.0 \mathrm{~m}$. Near the Miami area in the south-east coast of Florida, because wind directions were about parallel to the south-east Florida coast and the Florida Keys, no substantial increase of water levels were observed. Water levels were raised by about $0.2-0.6 \mathrm{~m}$ in Miami area, -0.6 to -1.0 near Fort Myers, and about -0.2 to -0.6 near the Tampa area.

At 23:00 UTC, September 10, $4 \mathrm{~h}$ after the hurricane landfall, the hurricane center moved to the Fort Myers area (Fig. 11). In the areas south of the hurricane center in south-west Florida, wind speeds were between 15 and $25 \mathrm{~m} / \mathrm{s}$ toward the coast of south-west Florida, and the maximum storm surge reached 2-2.5 $\mathrm{m}$. In the Miami area, water levels decreased by 0 to $-0.5 \mathrm{~m}$ because wind directions were away from the south-east coast of Florida. In the coastal areas between Fort Myers and Tampa (north of the hurricane center), wind directions were away from the coast, with speeds about $20-30 \mathrm{~m} / \mathrm{s}$. As a result, water levels from Fort Myers to Tampa decreased to about -0.5 and $-1 \mathrm{~m}$. This shows that, while wind hazards were the strongest near the hurricane center, the maximum storm surge was not in the hurricane center. Instead, the maximum storm surge was some distance to the south of the hurricane center.

At 3:00 UTC, September 11, the hurricane center moved north to the area between Tampa and Fort Myers (Fig. 12). Near the hurricane center, winds with speed of $25-30 \mathrm{~m} / \mathrm{s}$ moved southward approximately parallel to the coast. Wind direction was away from the coast in the areas north of the hurricane center, and was toward the coast in the south of the hurricane center. Wind speeds toward the coast have decreased to about $10-20 \mathrm{~m} / \mathrm{s}$. As a result, no obvious storm surges were observed on south Florida coast. In the coastal area north of Tampa and Tampa Bay, water levels decreased to about $-1.0 \mathrm{~m}$, resulting in negative storm surge because strong winds were away from the coast. Although winds continued to create hazardous effects, storm surge gradually reduced because of the reductions in the wind speeds as the weakened hurricane traveled north.

\section{Integrating storm surge and hurricane track forecasting with traffic analysis for hurricane evacuation assessment}

\subsection{Storm surge and wind analysis for determining} hurricane affected areas

Analysis of areas affected by storm surge and winds during Hurricane Irma can provide a good evaluation whether the evacuation operation was reasonable. The maximum storm surge along Florida coast during Hurricane Irma is shown in Fig. 13(a). Hurricane made landfall in south-west Florida as a Category 3 hurricane with maximum wind speed about $115 \mathrm{mph}$. The maximum surge from our model simulation is about 2.5 $\mathrm{m}$. The surge inundation did not reach the Federal Emergency Management Agency (FEMA) 100-year flood elevation (Fig. 13(b)), which has been used by the state for coastal construction permit and flood insurance.

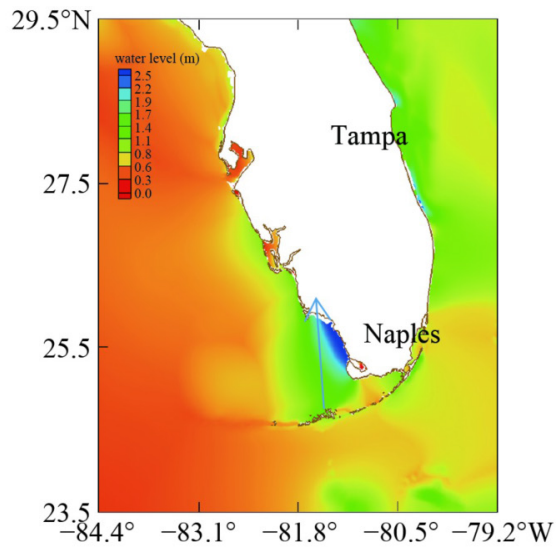

(a)

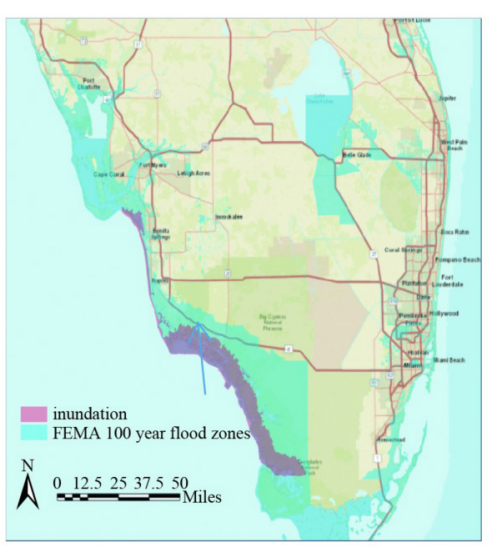

(b)

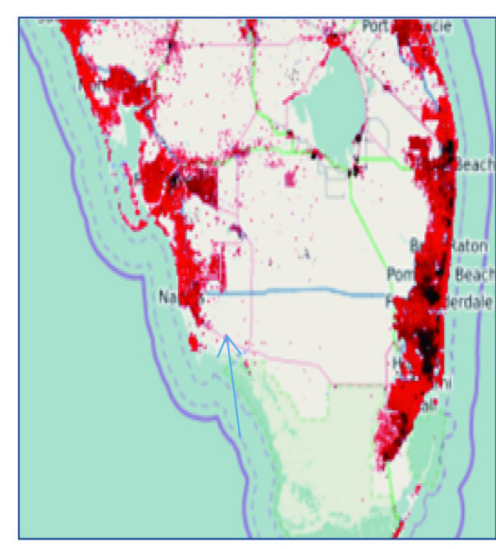

(c)

Fig. 13 (a) Moderate storm surge with maximum about $2.5 \mathrm{~m}$; (b) storm surge inundation showing below FEMA 100-year flood elevation for coastal construction permit and flood insurance; (c) population density distribution. 
Therefore, houses built above the 100-year flood elevation zone were not inundated by storm surges during Irma. In addition, as shown in the population density distribution (Fig. 13(c)), maximum storm surge occurred in the coastal area of Everglades National Park with almost no regular residents. The results are consistent with FEMA post-hurricane assessment [21].

When Hurricane Irma made landfall near Naples and Marco Island in south-west Florida, its strength decreased to Category 3 (115 mph) (Fig. 14(a)). As it continued moving north, it further decreased to Category 1 near Tampa [22], and then became a tropical storm as shown in Fig. 1. For building/house design and construction in south Florida coast, design wind speed in Florida Building Code (FBC) (2010) [23] is about $160-170 \mathrm{mph}$ (above Category 5) (Fig. 14(b)). In the Tampa area, design wind speed is $150 \mathrm{mph}$ in the coast and 140 inland (Category 4-5), which is far above the Category 1 winds that occurred when Hurricane Irma passed Tampa. Therefore, the design wind speed by FBC is far above Irma's wind speed in these areas as it moved north through Florida. Houses built by following FBC could resist the wind forces during Hurricane Irma. The analysis is consistent with FEMA's post hurricane assessments [21]. FEMA [21] found that Irma wind speeds did not approach the design wind speeds required in the last six editions of the FBC since 2002. The FEMA post-hurricane assessment team found that buildings designed and constructed complying with the FBC met expectations by performing well structurally during Hurricane Irma. For houses built before 2002, it is difficult to find reliable data for their general design wind speeds. The post-hurricane assessment reports by FEMA [21] show that most damaged homes were mobile homes or very old homes.

To approximately evaluate whether the evacuation of 6.8 million people during Hurricane Irma is reasonable or overreacted, we can approximately define the six coastal counties as shown in Fig. 14(c) (Monroe, Collier, Lee, Charlotte, and Sarasota, Manatee, and Hillsborough) as the hurricane hazard zone for evacuation of the entire population. Hurricane strength changed from Category 3 (115 mph) near Naples to Category $1(74-95 \mathrm{mph})$ in Sarasota and Manatee Counties. This already includes a very good safety factor because those living in houses/buildings above the 100-year flood zone and built after the effective FBC of 2002 were indeed safe for residents who stayed at home. In addition, for Category 1 hurricanes, common practice is to stay at home and board up windows, instead of evacuation [24]. The total population of those six counties is 2.25 million, which is only about $33 \%$ of the 6.8 million who relocated statewide during Hurricane Irma. Therefore, the evacuation during Hurricane Irma was a substantial overreaction. The overreacted evacuations were mainly caused by the uncertainty of hurricane forecasting and the unavailability of real-time forecasting and analysis of storm surge and winds for public access. Overreacted evacuations caused traffic congestions [19] and widespread gasoline shortage during Irma evacuation [25], which slowed down the evacuation.

5.2 Traffic analysis of overreacted evacuation during Hurricane Irma

Although the hurricane finally landed in south-west Florida with effects mainly in six coastal counties with a total population of 2.25 million, the overreacted statewide evacuation relocated about 6.8 million. As described in reports $[19,25]$, the massive evacuation during Hurricane Irma caused traffic congestions and widespread gasoline shortage. This section reports how real-time traffic data were used to analyze evacuation traffic patterns. The forecasts of hurricane tracks and affected areas from

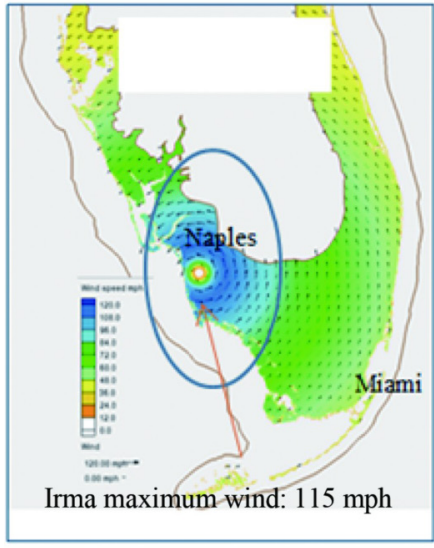

(a)

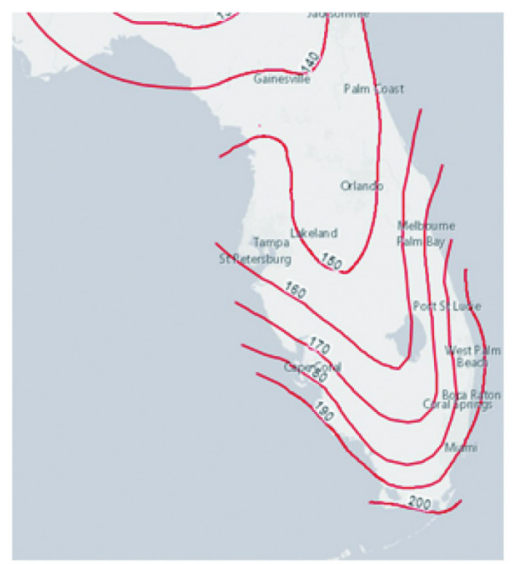

(b)

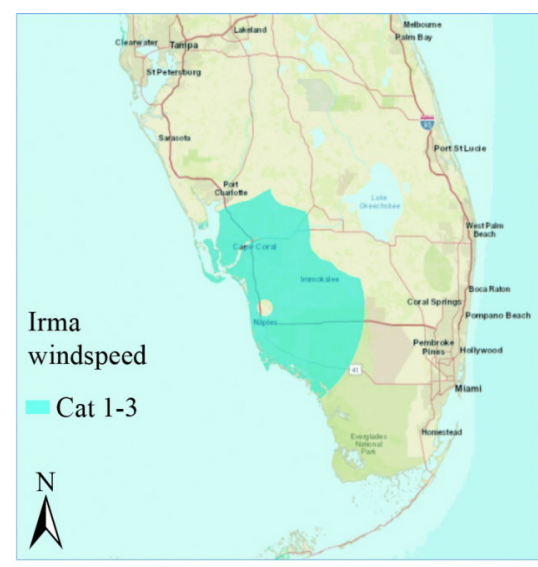

(c)

Fig. 14 (a) Wind field with maximum $115 \mathrm{mph}$ when Irma made landfall; (b) building design wind speed in FBC (150-170 mph, about Category 5 in south Florida coast, much larger than Irma's landfall wind speed of $115 \mathrm{mph}$, Category 3); (c) areas affected by Irma's CAT $1-3$ wind with total population about 2.25 million. 
National Hurricane Center (NHC) [22] were also presented to show how hurricane forecasting affected evacuation traffic. NHC's forecasted hurricane-affected area as shown in Figs. 15-19 do not have details of storm surge and wind speeds in the affected area.

A metric, namely the Evacuation Traffic Index (ETI), was defined to measure the level of change with respect to normal daily traffic for each roadway section on the studied highways before and during Irma's landfall. The ETI for a roadway section is defined as follows (Eq. (6)):

$$
\text { ETI }=\frac{\text { Evacuation Traffic }- \text { Normal Daily Traffic }}{\text { Normal Daily Traffic }} \times 100 \text {. }
$$

In addition, a Geographic Information Systems (GIS)based analysis was employed to visually illustrate the ETI values of corresponding highway sections with respect to different dates and times. The level of evacuation traffic change is simply presented as the percentage change of

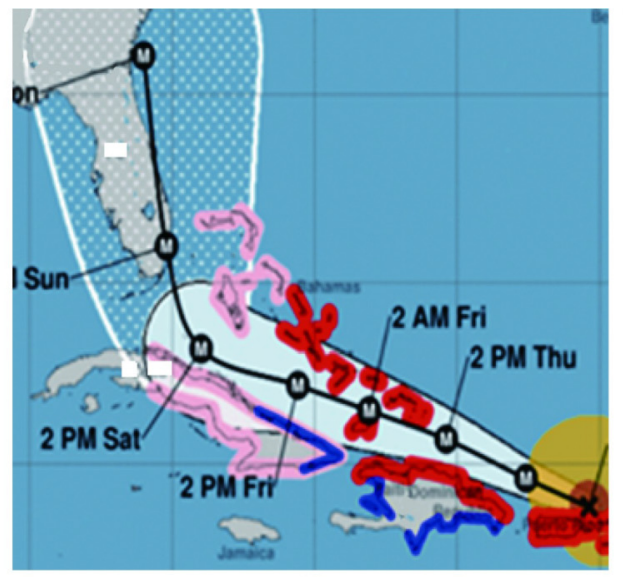

(a) traffic for the days before and during the hurricane event in September 2017 and those for the same days of September 2018. It is worth mentioning that 2018 hourly traffic volumes were the most updated data set, which was made publicly available by the FDOT at the time of conducting this study. The negative ETI values reveal that there is no traffic change compared to the daily traffic on that highway segment. On the other hand, the positive percentages show how much extra traffic was on the highways in comparison to an average day without evacuation traffic.

Traffic data were obtained from FDOT. Real-time data were collected by the FDOT TTMS from September 6 to September 10, 2017. In total, there are 63 TTMS located on the Florida's major highways, namely I-95, I-75, I-10, I-4, and turnpike (SR-91). The uncertainty in hurricane path forecasting [26] by NHC made it difficult for evacuation. As shown in Figs. 15-19, forecasted hurricane path shifted from east coast on September 6 to

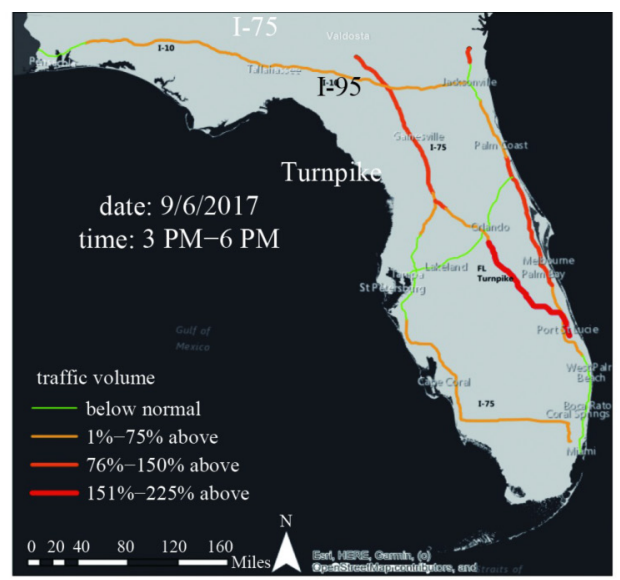

(b)

Fig. 15 (a) Hurricane track and affected coast (red lines) forecasted by NHC (left); (b) the ratio of traffic volume (right) on September 6 (4 $\mathrm{d}$ before landing).

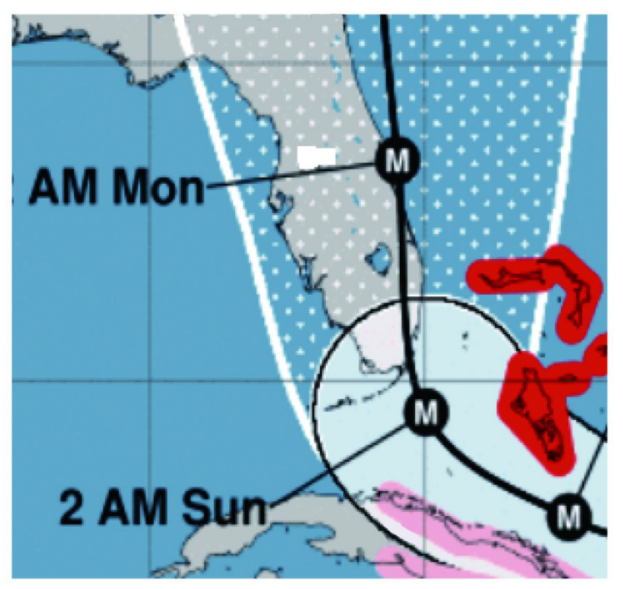

(a)

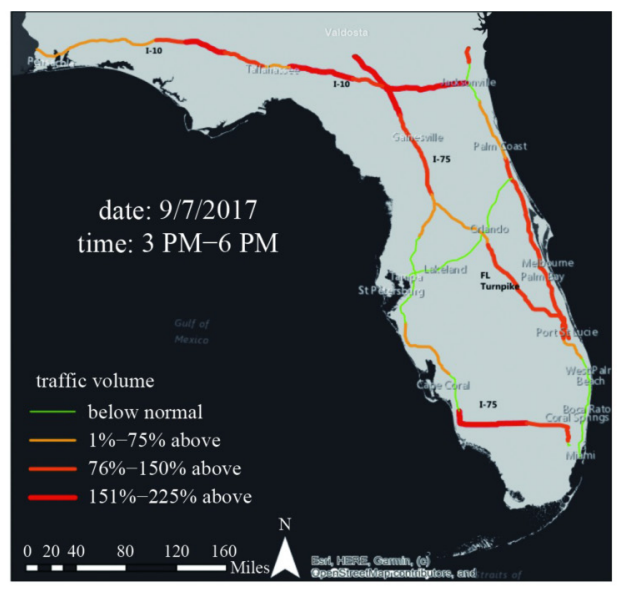

(b)

Fig. 16 (a) Hurricane track and affected coast (red area) forecasted by NHC (left panel); (b) the ratio of traffic volume (right panel) on September 7, 2017 (3 d before landing). 


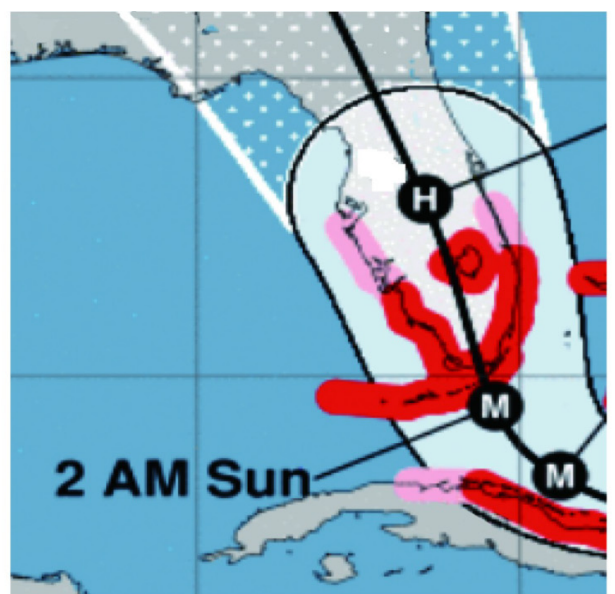

(a)

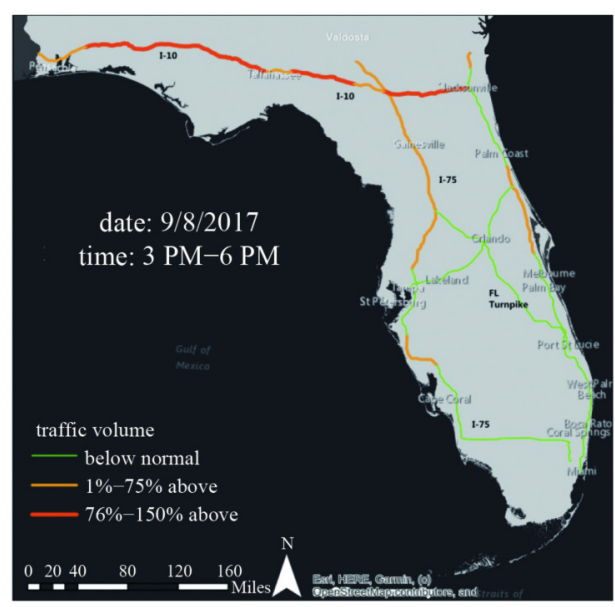

(b)

Fig. 17 (a) Hurricane track and affected coast (red lines) forecast by NHC ((left panel); (b) the ratio of traffic volume (right panel) on September 8, 2017 (2 d before landing).

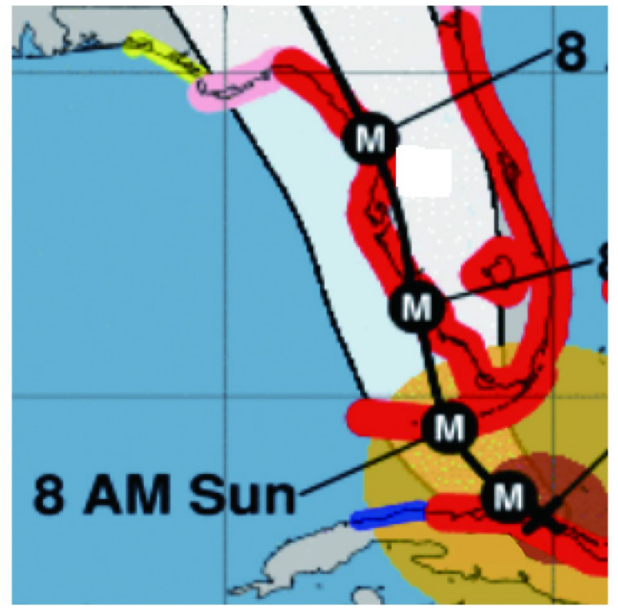

(a)

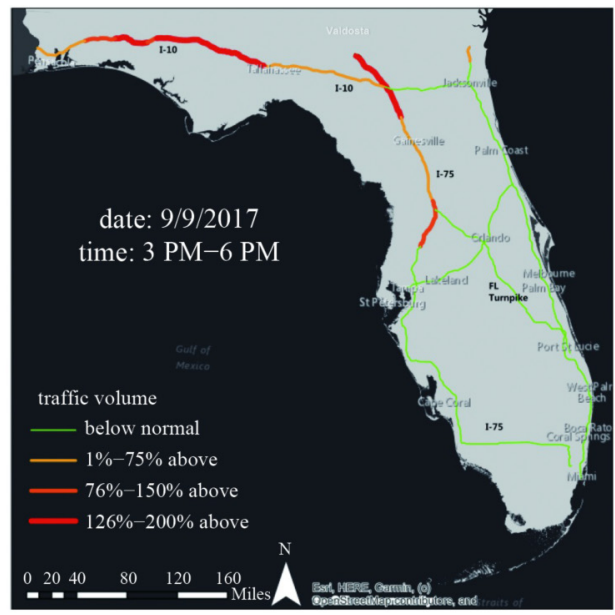

(b)

Fig. 18 (a) Hurricane track and affected coast (red area) forecasted by NHC ((left panel); (b) the ratio of traffic volume (right panel) on September 9, 2017 (1 d before landing).

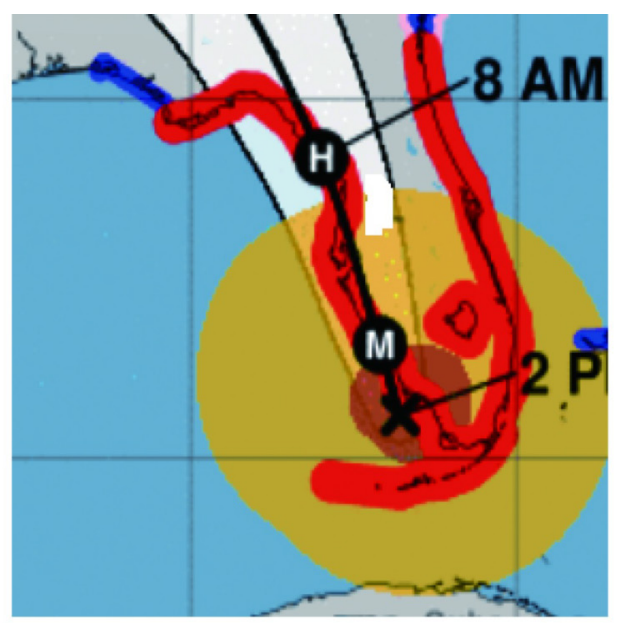

(a)

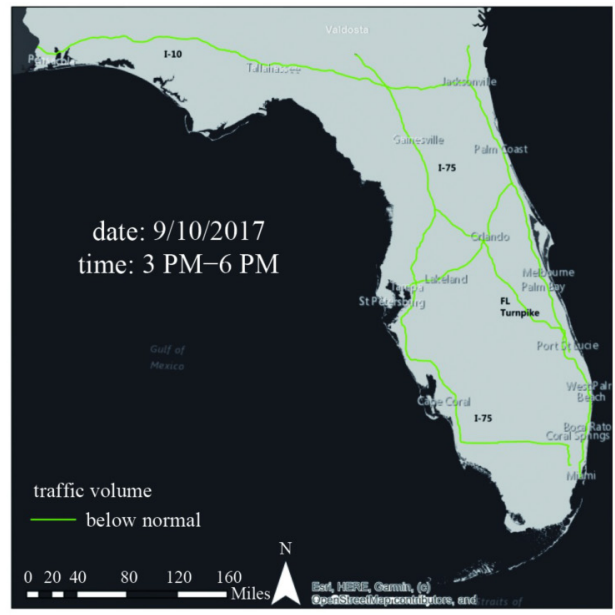

(b)

Fig. 19 (a) Hurricane track and affected coast (red area) forecasted by NHC ((left panel); (b) the ratio of traffic volume (right panel) when Irma landed on September 10, 2017. 
west coast on September 10. Before the hurricane made landfall in Florida, Florida officials ordered 6.8 million people to evacuate. There were 77000 people located in 450 shelters.

The evacuation caused traffic congestion. Four days before hurricane landing, the center of the hurricane path was forecast to be along Florida's east coast (Fig. 15(a)); people in south-east Florida started to move north along I-95 and north-east through Florida Turnpike (Fig. 15(b)). Above normal traffic was shown in I-75, Turnpike, and 195. Three days before the hurricane landfall, the forecast hurricane path was along the east coast toward the north (Fig. 16(a)). The congested traffic flow (Fig. 16(b)) with traffic volume above twice normal traffic volume shows that people in Florida east coast moved north and west to escape from hurricane impacts. However, because of the large number of vehicles during the evacuation, the traffic congestions made evacuation ineffective. The situation would have been improved if some people left 1-2 d earlier. Because the most probable projection of hurricane track was on the east coast of Florida on September 7, some residents in the east coast also moved to the west coast. Some residents living in the west coast such as in Fort Myers and Tampa Bay areas stayed at home until September 8 ( $2 \mathrm{~d}$ before hurricane landing), when the forecast hurricane track shifted toward the west coast.

Two days before hurricane landing, the NHC forecast a shift of hurricane track from east coast to central Florida (Fig. 17(a)). All coasts in south Florida were listed for potential storm surge impact. Traffic flow in southeastern Florida area (Fig. 17(b)) were below normal because most people completed the evacuation on September 7. However, along the east-west interstate highway I-10, the traffic volume was high, about 75\%-200\% above normal condition. This indicates that people drove west to escape from the hurricane impacts. Above normal traffic volume along I-75 north from Tampa indicates that residents in Tampa area continued to be evacuated. It also indicates that some residents did not leave on September 7 because of the forecast hurricane track on September 7 was along the east coast.

On September 9 ( $1 \mathrm{~d}$ before hurricane landfall), the $\mathrm{NHC}$ forecast the hurricane path shift to the west coast of south Florida, and all coasts in south Florida were listed for potential storm surge impacts (Fig. 18(a)). Traffic in south Florida was below normal condition because most of the residents had evacuated. Busy traffic was shown in north I-75 and I-10, indicating residents in central Florida were still leaving to the north and west to escape from the potential impact along the forecast hurricane path (Fig. 18(b)). The ratio of traffic volume in some sections of the interstate highway I-10 and I-75 were 126\%-200\% above normal traffic volume. On September 10 when Hurricane Irma made landfall in south-west Florida, all traffic in Florida was below normal condition (Fig. 19), indicating that the evacuation was almost complete.

In addition to the spatial analysis of ETI above, time series of traffic speed and volume during the evacuation period in 2017 at I-17 near Ocala-Gainesville [19] obtained from FDOT are presented in Fig. 20, showing how traffic speed was slowed down due to congestion. Comparison to the traffic volume during the same period in 2016 indicates a large increase of traffic volume during Hurricane Irma evacuation starting on September 6, $4 \mathrm{~d}$ before Hurricane Irma landing. Traffic congestions occurred on September 6 (average traffic speed of about $30 \mathrm{mph})$ and September $7(15 \mathrm{mph})$ in the state highway that requires minimum speed of $45 \mathrm{mph}$. FDOT opened the emergency shoulder to use on September 7 to ease the traffic congestion [19]. On September 7, general traffic speed was about 40-50 $\mathrm{mph}$, far below the normal $70 \mathrm{mph}$ before evacuation traffic starting at noon of September 6.

\section{Discussions}

Approximately 6.8 million people were ordered to evacuate [19]. Although the evacuation was successfully completed before the hurricane landing, some problems as shown below have been identified from this study that need to be addressed for the improvements of hurricane evacuations in the future.

a) Overreacted evacuation and traffic congestions caused by uncertainty of hurricane forecasting

As shown in Fig. 13, because Hurricane Irma made landfall in south-west Florida, a large percentage of evacuees in south-eastern Florida would have stayed at home if more accurate forecast information of hurricane track was provided. However, because the forecast central path of the hurricane 3-4 d before its landing was along the south-east coast (Figs. 15-16), many residents in south-east Florida coast evacuated. Some drove to south-west Florida area and later found out they were in the path of the shifted hurricane so that they had to move away again. Over-estimated evacuation was the major cause for evacuation traffic congestion that slowed down

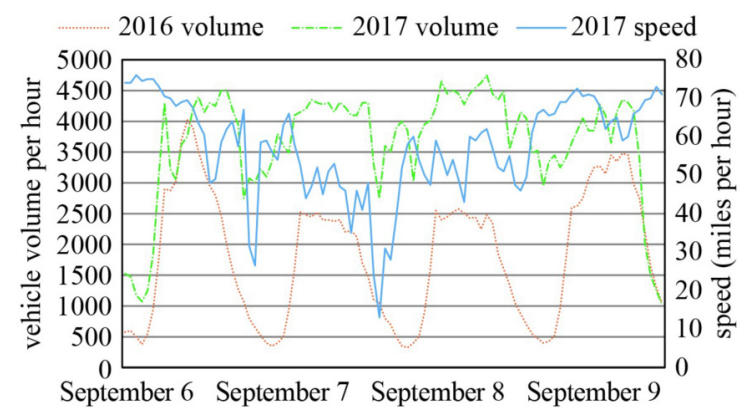

Fig. 20 I-75 Northbound traffic volumes show above highway traffic capacity at I-75 Ocala Station during evacuation in 2007. 
the evacuation. In addition, the worry of evacuation also caused widespread fuel shortage throughout the state of Florida [25], which made it difficult for those who really needed to evacuate. The uncertainty of track forecasting in advance (e.g., more than $3 \mathrm{~d}$ ) is largely due to the uncertainty of the forecast of the environmental factors themselves [27-29]. It may not be helpful for planning an evacuation a long time in advance (such as $4-5 \mathrm{~d}$ before the hurricane landing). As shown in the shift of Hurricane Irma track from south-east to south-west coast within $4 \mathrm{~d}$, those that traveled to the west coast had to make quick decisions to go back as the hurricane path changed toward their direction. Computational evacuation modeling can be used in the future to support evacuation operations in response to the uncertainty changes in hurricane forecasting.

b) Overreacted evacuation caused by lack of publically available real-time storm surge data

Figures 15-19 show general storm surge affected coastal area in the hurricane forecasting provided by NHC. Comparing to our storm surge model simulations, the general storm surge area by NHC does not give the magnitude of storm surge. Its affected areas cover a much larger area than our storm model simulations as evidenced by comparing Fig. 16 to Fig. 10. For the hurricane impacted area in south-west Florida, FEMA report [21] indicates that hurricane caused moderate flooding but was not considered a storm surge design event (i.e., exceedance of the 1-percent-annual-chance flood), which is consistent with our storm surge model result of maximum $2.5 \mathrm{~m}$ of moderate storm surge. This indicates that evacuation was unnecessary for residents living in houses built by following FEMA design flood elevation. However, due to the worry about the potential strong surge because of the lack of real time storm surge forecasting map for the public, many evacuated even though their houses were above the actual storm surge elevation, and this contributed to the traffic congestion. The storm surge model calibrated in this study will be able to provide real-time predictions of storm surge in the hurricane event in the future.

c) Overreacted evacuation caused by lack of familiarity with the FBC

Many residents may not have good knowledge of the wind load criteria for house/building design and construction as given in FBC. The first edition of FBC was published in 2002 [21] and has been continuously improved up to the latest 7th edition today [23], which aims to set the criteria for building strong houses to resist hurricane wind forces. Soon after Hurricane Irma, FEMA Mitigation Assessment Team (MAT) conducted building performance observations [21]. FEMA MAT focused primarily on one and two-family dwellings, but also assessed some multi-family dwellings (apartments and condominiums). They found that estimated wind speeds from Hurricane Irma in Florida did not approach the design wind speeds specified in the last six editions of the FBC, which is consistent with our wind field model as shown in Fig. 14. The FEMA team also found that buildings designed and constructed complying with the FBC met expectations by performing well structurally during Hurricane Irma. Therefore, residents living in houses designed and built after 2002 and following FBC should have been safe by staying at home without evacuation, if their houses were not located in coastal flood zone. However, the fears of wind damages made many residents evacuate, which increased the chances of evacuation traffic congestion and gasoline shortage.

Findings of this study provide valuable information for the improvement of hurricane evacuation planning and operations in the future to avoid overestimated evacuations. Overestimated massive evacuation can cause the shortage of gasoline and supplies like food and water, which became critical for those who really need to evacuate. The case study of coastal hazard and evacuation during Hurricane Irma indicates the need for interdisciplinary research. Findings of this research can help emergency management agencies to make more reliable decisions for hurricane evacuations.

\section{Conclusions}

Storm surge modeling and traffic analysis were conducted to evaluate the effectiveness of the evacuations during Hurricane Irma. The Category 5 hurricane caused a record evacuation with an estimated 6.8 million people relocating statewide in Florida. Coastal storm surge and wind analysis indicate that the scale of evacuation was overestimated. Only moderate storm tides (maximum about $2.5 \mathrm{~m}$ ) and maximum wind speed of about $115 \mathrm{mph}$ (Category 3) from model simulations are found to be consistent with FEMA post-hurricane assessment [21]. Storm surges did not reach 100-year flood elevation for coastal construction permit and the maximum wind was much below the design wind speed of 150-170 mph (Category 5) of FBC in south Florida coastal areas. The analysis from this study is consistent with FEMA's posthurricane observations of moderate flood and no structural damages for houses built after 2002 and after the FBC was implemented. Other than for the total population of about 2.25 million in the six coastal counties affected by storm surge and Category 1-3 wind, the statewide evacuation was considered an overreaction. Uncertainty of hurricane forecasting is one of the major factors for the overestimation of this evacuation, in addition to the lack of public awareness of real-time storm surge forecasting and the building strength against the wind.

Traffic data were used to analyze evacuation traffic 
patterns. Evacuation traffic started $4 \mathrm{~d}$ before the hurricane's arrival in south-east Florida. However, hurricane path shifted and eventually landed in southwest Florida, which caused massive evacuation traffic in south-west Florida. Evacuation almost completed in south Florida but continued in north Florida $1 \mathrm{~d}$ before the hurricane landfall. Traffic analysis indicates that evacuation traffic was mainly affected by the changes in forecast hurricane path. Overestimated large-scale evacuation caused traffic in excess of highways' traffic capacity, and that reduced the effectiveness of evacuations. Results from this study indicate that evacuation efficiency can be improved by more accurate hurricane forecasting, better public awareness of realtime storm surge and wind as well as evacuation modeling for quick response to the uncertainty of hurricane forecasting. Considering the uncertainty of hurricane forecasting, evacuation too early may add unnecessary traffic flow and gasoline consumption that may affect those who really need to evacuate.

\begin{abstract}
Acknowledgements This study was supported in part by National Science Foundation (Nos. 1832068 and 2101091) and Dr. Kai Yin conducted preliminary ADCIRC modeling study during his visit to FAMUFSU College of Engineering in 2018 before the NSF grant was awarded.
\end{abstract}

Open Access This article is licensed under a Creative Commons Attribution 4.0 International License (https:/creativecommons.org/licenses/ by/4.0/), which permits use, sharing, adaptation, distribution and reproduction in any medium or format, as long as you give appropriate credit to the original author(s) and the source, provide a link to the Creative Commons licence, and indicate if changes were made. The images or other third party material in this article are included in the article's Creative Commons licence, unless indicated otherwise in a credit line to the material. If material is not included in the article's Creative Commons licence and your intended use is not permitted by statutory regulation or exceeds the permitted use, you will need to obtain permission directly from the copyright holder. To view a copy of this licence, visit http://creativecommons.org/licenses/by/4.0/.

\section{References}

1. Ozguven E E, Horner M, Kocatepe A, Marcelin J M, Abdelrazig Y, Sando T, Moses R. Metadata-based needs assessment for emergency transportation operations with a focus on an aging population: A case study in Florida. Transport Reviews, 2016, 36(3): 383-412

2. Yazici M A, Ozbay K. Impact of probabilistic road capacity constraints on the spatial distribution of hurricane evacuation shelter capacities. Transportation Research Record: Journal of the Transportation Research Board, 2007, 2022(1): 55-62

3. Huang W, Hagen S, Bacopoulos P. Hydrodynamic modeling of Hurricane Dennis impact on estuarine salinity variation in Apalachicola Bay. Journal of Coastal Research, 2014, 30(2): 389-398
4. Xu S, Huang $\mathrm{W}$. Integrated hydrodynamic modeling and frequency analysis for predicting $1 \%$ storm surge in Pensacola Bay. Journal of Coastal Research, 2008, 52(Special Issue): 233-240

5. Xu S, Huang W, Zhang G, Gao F, Li X. Integrating Monte Carlo and hydrodynamic models for estimating extreme water levels by storm-surge in Colombo, Sri Lanka. Natural Hazards, 2014, 71(1): 703-721

6. Ullman D S, Ginis I, Huang W, Nowakowski C, Chen X, Stempel P. Assessing the multiple impacts of extreme hurricanes in southern New England, USA. Geosciences, 2019, 9(6): 265

7. Wang P, Adam J D, Cheng J, Vallee M. Morphological and sedimentological impacts of Hurricane Michael along the northwest Florida coast. Journal of Coastal Research, 2020, 36(5): 932-950

8. Shen Y, Deng G, Xu Z, Tang J. Effects of sea level rise on storm surge and waves within the Yangtze River Estuary. Frontiers of Earth Science, 2019, 13(2): 303-316

9. Ding Y, Ding T, Rusdin A, Zhang Y, Jia Y. Simulation and prediction of storm surges and waves using a fully integrated process model and a parametric cyclonic wind model. Journal of Geophysical Research: Oceans, 2020, 125(7): e2019JC015793

10. Wang T, Yang Z. The nonlinear response of storm surge to sealevel rise: A modeling approach. Journal of Coastal Research, 2019, 35(2): 287-294

11. Xiao H, Wang D, Medeiros S C, Bilskie M V, Hagen S C, Hall C R. Exploration of the effects of storm surge on the extent of saltwater intrusion into the surficial aquifer in coastal east-central Florida (USA). Science of the Total Environment, 2019, 648: 1002-1017

12. Pan Z, Liu H. Impact of human projects on storm surge in the Yangtze Estuary. Ocean Engineering, 2020, 196: 106792

13. Sun Z, Huang S, Nie H, Jiao J, Huang S, Zhu L, Xu D. Risk analysis of seawall overflowed by storm surge during super typhoon. Ocean Engineering, 2015, 107: 178-185

14. Li L, Yuan S, Amini F, Tang H. Numerical study of combined wave overtopping and storm surge overflow of HPTRM strengthened levee. Ocean Engineering, 2015, 97: 1-11

15. Roca M A, Brown R S, Solo-Gabriele H M. Fecal indicator bacteria levels at beaches in the Florida keys after Hurricane Irma. Marine Pollution Bulletin, 2019, 138: 266-273

16. Cangialosi J P, Latto A S, Berg R. Tropical Cyclone Report: Hurricane Irma, 30 August to 12 September 2017. National Hurricane Center. 2018

17. Bacopoulos P. Extreme low and high waters due to a large and powerful tropical cyclone: Hurricane Irma (2017). Natural Hazards, 2019, 98(3): 939-968

18. Carisio A, Kirk K, Lange R, Miller A. NOAA Water Level and Meteorological Data Report: Hurricane Irma U.S. Department of commerce, National Oceanic and Atmospheric Administration, National Ocean Service, Center for Operational Oceanographic Products and Services. 2018

19. The Florida Department of Transportation (FDOT). Hurricane Irma Emergency Evacuation Report and Recommendations. The Florida Department of Transportation, 2018 
20. Luettich R A, Westerink J J, Scheffner N W. ADCIRC: An Advanced Three-dimensional Circulation Model for Shelves, Coasts, and Estuaries. US Army Corps of Engineers, 1992

21. Federal Emergency Management Agency (FEMA). Hurricane Irma in Florida Building Performance Observations, Recommendations, and Technical Guidance. Mitigation Assessment Team Report FEMA P-2023. 2018

22. National Oceanic and Atmospheric Administration (NOAA), National Hurricane Center, 2017. IRMA Graphics Archive: 5-day Forecast Track, Initial Wind Field and Watch/Warning Graphic. 2017 (available at the website of National Hurricane Center)

23. Florida DBPR. Florida Building Code. 7th ed. 2020

24. Restoration S O S. What to do During a Category 1 Hurricane. (available at the website of RESTORATIONSOS)
25. Namilae S, Liu D, Parr S. Multiscale Model for Hurricane Evacuation and Fuel Shortage. Final Report June 2020. US Department of Transportation, 2000

26. National Hurricane Center (NHC). Hurricane Irma archive: 5-day forecast track. 2017. (available at the website of National Hurricane Center)

27. Chan J C. The physics of tropical cyclone motion. Annual Review of Fluid Mechanics, 2005, 37(1): 99-128

28. Chen Y, Zhang F, Green B W, Yu X. Impacts of ocean cooling and reduced wind drag on Hurricane Katrina (2005) based on numerical simulations. Monthly Weather Review, 2018, 146(1): 287-306

29. Shan K, Yu X. A simple trajectory model for climatological studies of tropical cyclones. Journal of Climate, 2020, 33(18): $7777-7786$ 